\title{
Oxidative Status in Epileptic Children Using Carbamazepine
}

\author{
Murat Tutanc, ${ }^{1}$ Mustafa Aras, ${ }^{2}$ Recep Dokuyucu, ${ }^{3,{ }^{*}}$ Murat Altas, ${ }^{2}$ Cem Zeren, ${ }^{4}$ Vefik Arica, \\ Oktay Hasan Ozturk, ${ }^{5}$ Sedat Motor, ${ }^{6}$ and Cahide Yilmaz ${ }^{1}$ \\ ${ }_{2}^{1}$ Department of Pediatrics, Mustafa Kemal University, Antakya, Hatay, Turkey \\ ${ }_{3}^{2}$ Department of Neurosurgery, Mustafa Kemal University, Antakya, Hatay, Turkey \\ ${ }^{3}$ Department of Physiology, Mustafa Kemal University, Antakya, Hatay, Turkey \\ ${ }_{5}^{4}$ Department of Forensic Medicine, Mustafa Kemal University, Antakya, Hatay, Turkey \\ ${ }^{5}$ Department of Biochemistry, Akdeniz University, Antalya, Turkey \\ ${ }^{6}$ Department of Biochemistry, Akdeniz University, Antalya, Turkey \\ ${ }^{*}$ Corresponding author: Recep Dokuyucu, Department of Physiology, Mustafa Kemal University, Antakya, Hatay, Turkey. Tel: +90-3262291000, Fax: +90-3262455654, \\ E-mail:drecepfatih@gmail.com
}

Received 2015 August 20; Accepted 2015 August 28

\begin{abstract}
Background: There is an increasing attention towards the relationship between oxidative stress and epilepsy. The effect of antiepileptic drugs on oxidant status is of major interest. Antiepileptic drugs can increase levels of free radicals, which consequently might lead to seizures. Carbamazepine (CBZ) is an antiepileptic drug commonly used in childhood and adolescence.

Objectives: Therefore we aimed to investigate the effects of CBZ on total antioxidant status, total oxidant stress, and oxidative stress index. Patients and Methods: The study included 40 epileptic patients and 31 healthy children between 4 and 12 years of age. Serum CBZ level, total antioxidant capacity and total oxidant status were measured. Oxidative stress index was also calculated both in controls and patients. Results: In the epileptic group, decreased levels of total antioxidant capacity, increased total oxidative stress and oxidative stress index levels were found. Positive correlation between plasma CBZ levels and total oxidant status was observed.

Conclusions: Antioxidant action could not be playing any role in antiepileptic effect of CBZ. Furthermore, increased oxidative stress induced by CBZ could be the cause of CBZ-induced seizures. Therefore combining CBZ with antioxidants could be beneficial.
\end{abstract}

Keywords: Carbamazepine, Antioxidant Capacity, Oxidant Status

\section{Background}

There are over 50 million epileptic patients all over the world according the data from world health organization (1). In the world, there are approximately 2.4 million new epileptic patients each year, of which at least 50\% begin in childhood and adolescence (1). In the treatment of partial and tonic-clonic seizures in children carbamazepine (CBZ) is reported to be effective equal to phenobarbitone, phenytoin and sodium valproate (1). Clinical recommendations in Europe and the USA suggest use of CBZ as first choice of treatment for partial epilepsies (2). However, CBZ was reported to increase lipid peroxide level and erythrocyte osmotic fragility (3).

Free radicals and lipid peroxides are involved in many physiological processes and pathogenesis of a number of diseases (4). The effects of antiepileptic drugs on generation of oxidative stress have also been investigated $(5,6)$. Free radicals attached irreversibly to proteins and deoxyribonucleic acid (DNA) macromolecules that are the primary targets for alkylation agents (6). They also cause degradation of DNA, nucleotide and structural coenzymes in cells and tissues. Furthermore, they can bind covalently to proteins, lipids and enzymes; consequently alter enzyme activities; corrupt cell membranes; and damage transport systems (7). The membrane lipid peroxidation due to an increase in free radicals or decrease in activities of antioxidant defense mechanisms has been suggested to be causally involved in some forms of epilepsy (7). On the other hand, malondialdehyde (MDA) values, an indicator of membrane lipid peroxidation, were found to be unchanged in children with epilepsy (8). Oxidative stress index (9) is reported as a valuable parameter indicating oxidative stress level. Furthermore, previously conducted studies revealed that oxidative stress index (OSI) rate indicates oxidative injury, as well (10-12).

Free radicals are eliminated by antioxidant systems. Total Antioxidative Status (TAS) determines the balance between the oxidative stress and antioxidant status. Measurement of total antioxidant capacity reflects the cumulative effect of antioxidants of plasma and body (13).

\section{Objectives}

Therefore the aim of this study was to evaluate the oxidative and antioxidative status in CBZ-treated epileptic children to improve the data regarding the connection between $\mathrm{CBZ}$ treatment and oxidative stress.

Copyright (C) 2015, Growth \& Development Research Center. This is an open-access article distributed under the terms of the Creative Commons Attribution-NonCommercial 4.0 International License (http://creativecommons.org/licenses/by-nc/4.0/) which permits copy and redistribute the material just in noncommercial usages, provided the original work is properly cited. 
Tutanc Met al.

\section{Patients and Methods}

The study is composed of 40 epileptic children (22 males, 18 females) and 31 healthy children (17 males, 14 females), with an age range between 4 and 12 years. All randomized subjects were selected from those who visited relating departments of Mustafa Kemal university faculty of medicine and Antakya State hospital for checkup or medical treatment. Patients that were included in the study were chosen among those with epileptic seizures receiving CBZ treatment for 1 year. The patients with systemic diseases (malignancy, diabetes mellitus, hypertension, autoimmune diseases, cardiac, metabolic, and central nerve ischemia), who use systemic and/or local corticosteroids were excluded. The research was approved by Mustafa Kemal university ethical committee.

\subsection{Biochemical Procedures}

$20 \mathrm{ml}$ of venous blood was obtained from each patient and controls. Then serum was separated by centrifugation at $3000 \mathrm{rpm}$ for $10 \mathrm{~min}$. Serum CBZ level was assessed using a biochemical auto analyzer (ARCHITECT c8000 Clinical Chemistry analyzer, Abbott $®$, U.S., Japan). Total oxidative status (TOS) (9) and TAS of serum was determined using a novel automated measurement method developed by Erel $(10,11)$. Oxidants present in the sample oxidize the ferrous ion-odianisidine complex to ferric ion. The oxidation reaction is enhanced by glycerol molecules, which are abundantly present in the reaction medium. The percent ratio of TOS to TAS yields the OSI, an indicator of the degree of oxidative stress (14). Percent rate of TOS level to TAS level was accepted as OSI (15). To apply the calculation, the result unit of TAS, mmol Trolox equivalent/l, was changed to mmol Trolox equivalent/l and the OSI value was calculated using following formula:

(1)

$$
\mathrm{OSI}=\frac{\mathrm{TOS}, \mathrm{mmol} \cdot \mathrm{L}^{-1}}{\mathrm{TAS}, \mathrm{mmol} \text { Trolox equivalent } . \mathrm{L}^{-1}} \times 100
$$

\subsection{Statistical Analysis}

Analysis of obtained data was performed using SPSS 13.0 for Windows, a statistical software package. Pearson correlation test was used for the correlation between blood CBZ level and blood TOS value. Correlation coefficient ( $r$ ) and significance values $(P)$ was determined. A P Value of $<0.05$ was accepted as significant.

\section{Results}

TAS, TOS and OSI levels of each group were compared, and statistically significant differences observed. TAS levels of CBZ treated group were significantly lower compared to those of the control group ( $\mathrm{P}<0.0001)$. Conversely, TOS and OSI levels were found to be significantly higher in CBZ treated group ( $\mathrm{P}<0.004$ and $\mathrm{P}<0.0001$, respectively) (Table 1). In CBZ treated epileptic patients' group, correlation between blood CBZ level and TAS-TOS levels was examined. A positive correlation was found between CBZ and TOS levels $(r=0.472, P<0.01$ ) (Figure 1$)$. However, no significant correlation was detected between blood CBZ and TAS levels.

\begin{tabular}{lccc}
\hline \multicolumn{4}{c}{ Table 1. TAS, TOS and OSI Values of CBZ and Control Groups } \\
\hline & CBZ group $(\mathbf{n}=\mathbf{4 0})$ & Control $(\mathbf{n}=\mathbf{3 1})$ & P Value \\
\hline TAS & $1.29 \pm 0.23$ & $1.52 \pm 0.13$ & $<0.0001$ \\
TOS & $1.41 \pm 0.49$ & $1.08 \pm 0.42$ & $<0.004$ \\
OSI & $111.4 \pm 0.42$ & $72.4 \pm 30.1$ & $<0.0001$ \\
\hline
\end{tabular}

${ }^{a}$ Abbreviations: CBZ, carbamazepine; OSI, oxidative stress index; TAS, total antioxidant status; TOS, total oxidant status.

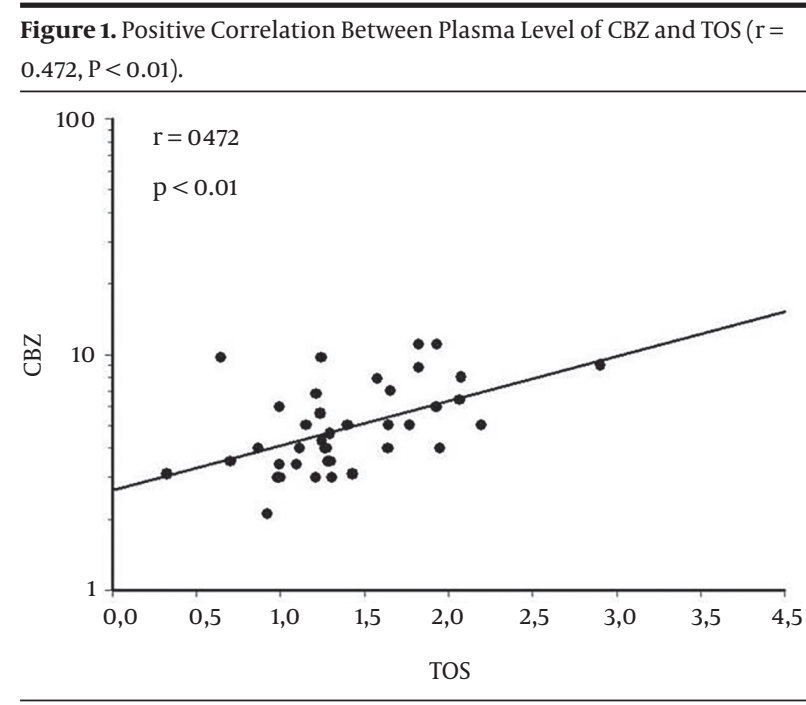

CBZ: carbamazepine; TOS: total oxidant status.

\section{Discussion}

Our study showed that CBZ treatment increased oxidative stress in patients with epilepsy. In the literature, there is a limited number of clinical case studies investigating the relation between oxidative stress and CBZ treatment in patients with epilepsy (16-20). Our study differed in several aspects from those in the literature. First of all number of cases in the present study is higher. Secondly, we firstly evaluated the relationship between oxidative stress and CBZ treatment with TAS, TOS and OSI measurement in epileptic patients.

Li et al. (21) investigated the effects of CBZ on the oxidative stress of common carp spermatozoa in vitro. They reported that the oxidative stress was apparent and the significant inhibition of antioxidant enzymes activities including superoxide dismutase (SOD) and glutathione peroxidase (GSH-Px) after 2 hours exposure of $\mathrm{CBZ}$ at higher concentration $(2.0$ or $20 \mathrm{mg} / \mathrm{L})$. Their results suggested that CBZ can induce reactive oxygen species (20) stress and could impair the antioxidant defense system. Li et al. (22) also investigated the effect of long-term exposure to $\mathrm{CBZ}$ on the antioxidant system in brain tissue of rainbow trout. The fish were exposed to sublethal concentrations of CBZ (1.0 $\mu \mathrm{g} / \mathrm{L}, 0.2 \mathrm{mg} / \mathrm{L}$ or $2.0 \mathrm{mg} / \mathrm{L}$ ) for 7, 21, and 42 days. CRZ exposure at $0.2 \mathrm{mg} / \mathrm{L}$ led to significant 
increases of oxidative stress indices after 42 days and, at $2.0 \mathrm{mg} / \mathrm{L}$, after 21 days. Activities of the antioxidant enzymes including SOD, CAT, and GPX in CBZ-treated groups slightly increased during the first period (7 days). However, activities of antioxidant enzymes were significantly inhibited at $0.2 \mathrm{mg} / \mathrm{L}$ exposure after 42 days and after 21 days at $2.0 \mathrm{mg} / \mathrm{L}$. After 42 days, the content of glutathione (GSH) in fish brain was significantly lower in groups exposed to CBZ at $0.2 \mathrm{mg} / \mathrm{L}$ and $2.0 \mathrm{mg} / \mathrm{L}$. Prolonged exposure to CBZ resulted in excess reactive oxygen species formation, finally resulting in oxidative damage to lipids and proteins and inhibited antioxidant capacities in fish brain. The authors emphasized that a low level of oxidative stress could induce the adaptive responses of antioxidant enzymes, but long-term exposure to CBZ could lead to serious oxidative damage in fish brain.

Oxidative stress is the condition with an imbalance between generation and elimination of ROS and reactive nitrogen species, creating the potential for organic damage. Oxidative stress is blamed for the pathogenesis of epilepsy as a potential mechanism (23). Liang and Patel (24) have demonstrated that persistent seizures caused oxidative damage. Several studies on animal models and genetic studies have demonstrated an increase in mitochondrial oxidative stress and subsequent cell damage after persistent seizures (24-26).

Oxidative stress may be caused by various diseases or exposure to certain chemicals. It has been reported that the increased amount of active oxygen metabolites or reduced activity of antioxidative defense mechanisms may cause greater frequency of seizure $(7,27)$. Antioxidative systems suppress this oxidative stress (12). This mechanism protects the organism against the harmful effects of the chemicals.

The role of antioxidant action in the effect of antiepileptic drugs (AEDs) is controversial. Hamed and Abdellah (28) reviewed the relation between membrane lipid peroxidation, antioxidants, neuronal excitotoxicity, and AEDs. The authors identified that CBZ was found to be a better anti-epileptic for the control of free radical-related seizures. On the other hand, Solowiej (29) reported that SOD activity decreased, GSH-Px, glutathione disulfide (GSSG-R) activities and MDA level increased in the serum of children and adolescents with epilepsy.

According Niketic (30), the activity of antioxidant enzymes were decreased by $40 \%$ in epileptic children on CBZ compared to healthy individuals. However, increased TOS was observed in the same study. Certain studies noted that phenytoin (31) and valproic acid treatment (32) increase lipid peroxidation in epileptic children. Increased TOS and decreased TAS were also demonstrated by some in vitro studies $(21,22)$. Oxidative damage caused by CBZ was revealed by some previously conducted studies $(16,17)$.

We found increased TOS and OSI levels in patients receiving 1 year CBZ treatment. Different from the literature, our findings are based on TAS, TOS and OSI measurements for the first time. Therefore, we discussed our results in the light of related literature. Both the role of antioxidant action in epilepsy pathogenesis and the effect of AEDs, particularly CBZ, on the oxidant-antioxidant status in epilepsy patients are controversial. This could be due to complex pathogenic mechanisms of epilepsy and methodological issues. Yet oxidative stress may originate from various sources in the body and peripheral measurements might not necessarily accurately reflect the oxidative stress in the central nervous system. Another contribution of our study is that the relationship between the CBZ levels and oxidative damage was firstly evaluated in the present study. A positive correlation was observed between plasma CBZ levels and oxidative damage. This finding might be an explanation for oxidative damage secondary to CBZ treatment, and for efficacy of antioxidants (17). There was no control group of epileptic patients without treatment in the study. This is a limitation of our study.

Epilepsy has a multifactorial mechanism and it is difficult to isolate a single cause of the disease. Therefore the mechanism of action of AEDs could not be fully understood yet. Based on our results, antioxidant mechanism could not be playing any role in antiepileptic effect of CBZ. Furthermore, increased oxidative stress induced by CBZ could be the cause of carbamazepine-induced seizures, a complication of CBZ treatment. Therefore combining CBZ with antioxidants could be beneficial.

\section{Footnote}

Authors' Contribution:Murat Tutanc: Study Design; Mustafa Aras: Data Collection; Recep Dokuyucu: Manuscript Preparation; Murat Altas: Data Collection; Cem Zeren: Statistical Analysis; Vefik Arica: Literature Search; Oktay Hasan Ozturk: Biochemical Analysis; Sedat Motor: Biochemical Analysis; Cahide Yilmaz: Data Collection.

\section{References}

1. WHO Carbamazepine In Childhood Epilepsy. The World Health Organization. Report prepared for the World Health Organization. 2006. Available from: http:/|archives.who.int/eml/expcom/expcom15/ applications/paediatrics/formulations/Carbamazepine.pdf.

2. Guideline SNC. Diagnosis and Management of Epilepsies in Children and Young People, in Scottish National Clinical Guideline. Scottish Intercollegiate Guidelines Network; 2005.

3. Yalçin A, Onaran İ, Yalçin A. Effect of antiepileptic drugs on erythrocyte osmotic fragility and lipid peroxidation. Epilepsy Res. 1994;19(3):249-52. doi: 10.1016/0920-1211(94)90069-8. [PubMed: 7698102]

4. Bast A, Haenen GR, Doelman CJ. Oxidants and antioxidants: State of the art.Am J Med.1991;91(3):S2-S13. doi:10.1016/0002-9343(91)90278-6.

5. Arroyo S, de la Morena A. Life-threatening adverse events of antiepileptic drugs. Epilepsy Res. 2001;47(1-2):155-74. doi: 10.1016| s0920-1211(01)00306-0. [PubMed:11673030]

6. Del Maestro RF. An approach to free radicals in medicine and biology. Acta Physiol Scand Suppl. 1980;492:153-68. [PubMed: 6261528]

7. Jesberger JA, Richardson JS. Oxygen Free Radicals and Brain Dysfunction. Int $J$ Neurosci. 1991;57(1-2):1-17. doi: 10.3109/00207459109150342. [PubMed:1938149]

8. Ramaekers VT, Bosman B, Jansen GA, Wanders RJ. Increased plasma malondialdehyde associated with cerebellar structural defects. Arch Dis Child.1997;77(3):231-4. [PubMed: 9370902] 
9. Potrebic O, Jovic-Stosic J, Vucinic S, Tadic J, Radulac M. [Acute glyphosate-surfactant poisoning with neurological sequels and fatal outcome]. Vojnosanit Pregl. 2009;66(9):758-62. [PubMed: 19877558]

10. Erel O. A novel automated direct measurement method for total antioxidant capacity using a new generation, more stable ABTS radical cation. Clin Biochem. 2004;37(4):277-85. doi: 10.1016/j.clinbiochem.2003.11.015. [PubMed:15003729]

11. Erel O. A new automated colorimetric method for measuring total oxidant status. Clin Biochem. 2005;38(12):1103-11. doi:10.1016/j. clinbiochem.2005.08.008. [PubMed:16214125]

12. McCord JM. The evolution of free radicals and oxidative stress Am J Med. 2000;108(8):652-9. doi: 10.1016/s0002-9343(00)004125. [PubMed: 10856414]

13. Ghiselli A, Serafini M, Natella F, Scaccini C. Total antioxidant capacity as a tool to assess redox status: critical view and experimental data. Free Radical Biol Med. 2000;29(11):1106-14. doi: 10.1016/s0891-5849(00)00394-4. [PubMed:11121717]

14. Kosecik M, Erel O, Sevinc E, Selek S. Increased oxidative stress in children exposed to passive smoking. Int JCardiol.2005;100(1):614. doi:10.1016/j.ijcard.2004.05.069. [PubMed:15820286]

15. Kawachi I, Colditz GA, Speizer FE, Manson JE, Stampfer MJ, Willett WC, et al. A prospective study of passive smoking and coronary heart disease. Circulation. 1997;95(10):2374-9. [PubMed: 9170399]

16. Cengiz M, Yuksel A, Seven M. The effects of carbamazepine and valproic acid on the erythrocyte glutathione, glutathione peroxidase, superoxide dismutase and serum lipid peroxidation in epileptic children. Pharmacol Res. 2000;41(4):423-5. doi:10.1006 phrs.1999.0603. [PubMed:10704266]

17. Gupta M, Gupta YK, Agarwal S, Aneja S, Kalaivani M, Kohli K. Effects of add-on melatonin administration on antioxidant enzymes in children with epilepsy taking carbamazepine monotherapy: a randomized, double-blind, placebo-controlled trial. Epilepsia. 2004;45(12):1636-9. doi: 10.1111/j.0013-9580.2004.17604.x. [PubMed:15571523]

18. Isik M, Demir Y, Kirici M, Demir R, Simsek F, Beydemir S. Changes in the anti-oxidant system in adult epilepsy patients receiving anti-epileptic drugs. Arch Physiol Biochem. 2015;121(3):97-102. doi: 10.3109/13813455.2015.1026912. [PubMed: 26120045]

19. Naziroglu M, Yurekli VA. Effects of antiepileptic drugs on antioxidant and oxidant molecular pathways: focus on trace elements. Cell Mol Neurobiol. 2013;33(5):589-99. doi:10.1007/s10571-013-99365. [PubMed: 23584684]

20. Stockis A, Chanteux H, Rosa M, Rolan P. Brivaracetam and carbamazepine interaction in healthy subjects and in vitro. Epilepsy Res. 2015;113:19-27. doi: 10.1016/j.eplepsyres.2015.03.003. [PubMed: 25986188]

21. Li ZH, Li P, Rodina M, Randak T. Effect of human pharmaceutica Carbamazepine on the quality parameters and oxidative stress in common carp (Cyprinus carpio L.) spermatozoa. Chemosphere 2010;80(5):530-4.doi: $\quad$ 10.1016/j.chemosphere.2010.04.046. [PubMed: 20466407]

22. Li ZH, Zlabek V, Velisek J, Grabic R, Machova J, Randak T. Modulation of antioxidant defence system in brain of rainbow trout (Oncorhynchus mykiss) after chronic carbamazepine treatment Comp Biochem Physiol C Toxicol Pharmacol. 2010;151(1):137-41. doi: 10.1016/j.cbpc.2009.09.006. [PubMed:19778632]

23. Chang SJ, Yu BC. Mitochondrial matters of the brain: mitochondrial dysfunction and oxidative status in epilepsy. J Bioenerg Biomembr. 2010;42(6):457-9. doi: 10.1007/s10863-010-9317-4. [PubMed: 21086030]

24. Liang LP, Patel M. Seizure-induced changes in mitochondrial redox status. Free Radic Biol Med. 2006;40(2):316-22. doi: 10.1016/j. freeradbiomed.2005.08.026. [PubMed:16413413]

25. Bruce AJ, Baudry M. Oxygen free radicals in rat limbic structures after kainate-induced seizures. Free Radical Biol Med. 1995;18(6):993-1002. doi: 10.1016/0891-5849(94)00218-9. [PubMed: 7628735

26. Gluck MR, Jayatilleke E, Shaw S, Rowan AJ, Haroutunian V. CNS oxidative stress associated with the kainic acid rodent model of experimental epilepsy. Epilepsy Res. 2000;39(1):63-71. doi:10.1016 s0920-1211(99)00111-4. [PubMed:10690755]

27. Willmore LJ, Rubin JJ. Antiperoxidant pretreatment and ironinduced epileptiforom discharges in the rat: EEG and histopathologic studies. Neurology. 1981;31(1):63. doi: 10.1212/wnl.31.1.63. [PubMed: 7192826]

28. Hamed S, Abdellah MM. Trace Elements and Electrolytes Homeostasis and Their Relation to Antioxidant Enzyme Activity in Brain Hyperexcitability of Epileptic Patients. J Pharmacol Sci. 2004;96(4):349-59. doi: 10.1254/jphs.CRJ04004X. [PubMed 15599105]

29. Solowiej E, Sobaniec W. [The effect of antiepileptic drug therapy on antioxidant enzyme activity and serum lipid peroxidation in young patients with epilepsy]. Neurol Neurochir Pol. 2003;37(5):991-1003. [PubMed: 15174247]

30. Niketic V, Ristic S, Saicic ZS, Spasic M, Buzadzic B, Stojkovic M Activities of antioxidant enzymes and formation of the glutathione adduct of hemoglobin (Hb ASSG) in epileptic patients with long-term antiepileptic therapy. Farmaco. 1995;50(11):811-3. [PubMed: 8593178]

31. Mahle C, Dasgupta A. Decreased total antioxidant capacity and elevated lipid hydroperoxide concentrations in sera of epileptic patients receiving phenytoin. Life Sci. 1997;61(4):437-43. doi 10.1016/s0024-3205(97)00401-3. [PubMed: 9244370]

32. Peker E, Oktar S, Ari M, Kozan R, Dogan M, Cagan E, et al. Nitric oxide, lipid peroxidation, and antioxidant enzyme levels in epileptic children using valproic acid. Brain Res. 2009;1297:194-7. doi: 10.1016/j.brainres.2009.08.048. [PubMed:19703427] 